\title{
The Value of Total Body Photography for the Early Detection of Melanoma: A Systematic Review
}

\author{
Annkathrin Hornung ${ }^{1,2,+}$, Theresa Steeb ${ }^{1,2,+} \oplus$, Anja Wessely ${ }^{1,2}$, Titus J. Brinker ${ }^{3}$, Thomas Breakell ${ }^{1,2}{ }^{(0}$, \\ Michael Erdmann ${ }^{1,2}{ }^{(0)}$, Carola Berking ${ }^{1,2}$ and Markus V. Heppt ${ }^{1,2, *(1)}$
}

1 Department of Dermatology, Universitätsklinikum Erlangen, Friedrich-Alexander-University Erlangen-Nürnberg (FAU), 91054 Erlangen, Germany; Annkathrin.Hornung@uk-erlangen.de (A.H.); Theresa.Steeb@uk-erlangen.de (T.S.); Anja.Wessely@uk-erlangen.de (A.W.); breakell.tom@gmail.com (T.B.); michael.erdmann@uk-erlangen.de (M.E.); carola.berking@uk-erlangen.de (C.B.)

2 Comprehensive Cancer Center Erlangen-European Metropolitan Region of Nürnberg, 91054 Erlangen, Germany

3 Digital Biomarkers for Oncology Group, National Center for Tumor Diseases (NCT), German Cancer Research Center (DKFZ), 69120 Heidelberg, Germany; titus.brinker@nct-heidelberg.de

* Correspondence: markus.heppt@uk-erlangen.de; Tel.: +49-913-1853-5747

+ Equal authorship contribution.

Citation: Hornung, A.; Steeb, T.; Wessely, A.; Brinker, T.J.; Breakell, T.; Erdmann, M.; Berking, C.; Heppt, M.V. The Value of Total Body Photography for the Early Detection of Melanoma: A Systematic Review. Int. J. Environ. Res. Public Health 2021, 18, 1726. https://doi.org/10.3390/ ijerph18041726

Academic Editor: Paul B. Tchounwou Received: 13 January 2021

Accepted: 4 February 2021

Published: 10 February 2021

Publisher's Note: MDPI stays neutral with regard to jurisdictional claims in published maps and institutional affiliations.

Copyright: (c) 2021 by the authors. Licensee MDPI, Basel, Switzerland. This article is an open access article distributed under the terms and conditions of the Creative Commons Attribution (CC BY) license (https:/ / creativecommons.org/licenses/by/ $4.0 /)$.

\begin{abstract}
Early detection of melanoma is critical to reduce the mortality and morbidity rates of this tumor. Total body photography (TBP) may aid in the early detection of melanoma. To summarize the current evidence on TBP for the early detection of melanoma, we performed a systematic literature search in Medline, Embase, and the Cochrane Central Register of Controlled Trials (CENTRAL) for eligible records up to 6th August 2020. Outcomes of interest included melanoma incidence, incisional and excisional biopsy rates, as well as the Breslow's index of detected tumors. Results from individual studies were described qualitatively. The risks of bias and applicability of the included studies was assessed using the QUADAS-2 checklist. In total, 14 studies published between 1997 and 2020 with an overall sample size of $n=12,082$ (range 100-4692) were included in the qualitative analysis. Individuals undergoing TBP showed a trend towards a lower Breslow's thickness and a higher proportion of in situ melanomas compared to those without TBP. The number needed to excise one melanoma varied from 3:1 to 14.3:1 and was better for lesions that arose de novo than for tracked ones. The included studies were judged to be of unclear methodological concern with specific deficiencies in the domains "flow and timing" and "reference standard". The use of TBP can improve the early detection of melanoma in high-risk populations. Future studies are warranted to reduce the heterogeneity of phenotypic risk factor definition and the technical implementation of TBP. Artificial intelligence-assisted analysis of images derived from 3-D TBP systems and digital dermoscopy may further improve the early detection of melanoma.
\end{abstract}

Keywords: artificial intelligence; early detection; melanoma; photography; prevention; skin cancer; total body photographic cutaneous surveillance

\section{Introduction}

The incidence of cutaneous melanoma continues to rise steadily in Western countries with Caucasian populations each year [1,2]. Surgical treatment is usually curative following early detection of the disease [3,4]. However, melanoma quickly becomes life-threatening once it metastasizes [3], although considerable progress has been made following novel therapeutic interventions including BRAF and MEK inhibitors and immunotherapies [5,6]. Thus, early detection of cutaneous lesions remains of paramount importance to significantly reduce the morbidity and mortality caused by melanoma, as thinner primary tumors are associated with an improved survival rate [7-9]. Hence, strategies to improve early detection are critical in patients at high risk for melanoma. 
In Germany, the worldwide unique national skin cancer screening program was implemented in 2008. It involves a voluntary, standardized full-body examination by dermatologists or general practitioners specifically trained for this purpose. The costs are reimbursed by all German statutory health insurance companies every two years for members older than 35 years, while some health insurance companies also cover the costs for younger members [10]. Instead of mass screening of an entire population, other approaches aim to selectively identify and surveil individuals at the highest risk for melanoma [11,12]. One of the most promising approaches involves automated imaging of patients or total body photography (TBP), allowing objective documentation of all existing lesions and monitoring changes over time. TBP uses clinical photography of the patients' skin surface to provide a photographic record. This can be achieved by either 2-D or 3-D TBP. In 2-D TBP, common 2-D images of the skin are taken and composed to a body map while a 3-D representation of the patient's surface is created in 3-D TBP, partly even linked with dermoscopy images. Thus, 3-D TBP may particularly facilitate the localization of lesions for follow-up [13]. Both techniques may aid in the assistance of the early detection of melanoma as they improve the diagnostic accuracy of melanoma in high-risk patients [14-17]. TBP has the advantage of monitoring the patient's entire skin surface, rather than only a subset of individual lesions. Furthermore, TBP can be combined with sequential digital dermoscopy imaging (SDDI) as this "two-step approach" might provide more intensive surveillance in high-risk patients to assist with an early melanoma diagnosis.

However, until now, the value of TBP in the early detection of melanoma has not been systematically investigated. Here we performed a systematic review to summarize the current publication landscape of TBP in the prevention of melanoma. Our results will assist dermatologists as well as patients in choosing an appropriate and individual screening and surveillance strategy.

\section{Materials and Methods}

This review was conducted in accordance with the Preferred Reporting Items for Systematic Reviews and Meta-Analyses (PRISMA) [18], its extension for diagnostic test accuracy $[19,20]$, and the Cochrane Handbook for Systematic Reviews [21].

\subsection{Eligibility Criteria}

We included studies investigating patients of any age with common melanocytic nevi (moles), congenital nevi, or dysplastic/atypical nevi undergoing 2-D TBP or 3-D TBP to detect melanoma early as part of screening for surveillance. Combination with other diagnostic measures, such as physical examination, self-examination, or SDDI was allowed but not obligatory for inclusion. In addition, studies investigating only TBP for keratinocyte cancer were excluded from the analysis.

Regarding the study design, we included randomized controlled trials (RCTs), clinically controlled trials (CCTs), non-controlled prospective trials, prospective observational studies, case-control studies as well as retrospective studies. Narrative reviews and case reports or series were excluded. No language restrictions were set. In RCTs and controlled observational studies, usual care served as control. If no control group was specifically included, data from external control groups or the general population served as control.

\subsection{Types of Outcome Measures}

The outcomes of interest were all related to the early detection of melanoma. Thus, the incidence of melanoma, the number of excisions and biopsies, the number of changed or new nevi, as well as the benign-to-malignant ratio of excised lesions were defined as outcomes of interest. Additionally, the mean or median vertical invasion depth measured in $\mathrm{mm}$ (Breslow's index) of detected melanomas was considered as an outcome. As we expected heterogeneously reported outcomes, we extracted the data as reported in the publication and did not perform any re-calculations. 


\subsection{Search Methods for Identification of Studies}

We searched the electronic databases Medline, Embase (both via Ovid), and the Cochrane library CENTRAL until 6 August 2020 to identify all possibly relevant records (Table 1). For ongoing trials and completed trials without data publication, principal investigators or trial sponsors were contacted to obtain preliminary or unpublished data. Moreover, reference lists of included records and evidence- and consensus-based guidelines on the diagnosis of melanoma were screened.

Table 1. Detailed Strategy of the Literature Identification Process.

Ovid MEDLINE(R) and Epub Ahead of Print, In-Process \& Other Non-Indexed Citations, Daily and Versions(R) 1946 to 4 August $2020 n=255$

1. $\quad$ exp Imaging, Three-Dimensional/ or vectra.mp. ${ }^{1}$

2. whole Body photography.mp.

3. 3D total Body photography.mp.

4. total-Body 3D photography.mp.

5. complete Body photography.mp.

6. Body photography.mp.

7. exp Skin Neoplasms/ or exp Melanoma/ or cutaneous melanoma.mp.

8. 1 or 2 or 3 or 4 or 5 or 6

9. 7 and 8

Embase 1974 to 2020 Week 31, $n=1283$

1. vectra.mp.

2. Three-Dimensional Imaging.mp. or exp three-dimensional imaging/ or exp image processing/

3. whole Body photography.mp.

4. $\quad$ exp imaging system/ or 3D total Body photography.mp.

5. total-Body 3D photography.mp.

6. complete Body photography.mp.

7. Body photography.mp

8. exp skin cancer/ or cutaneous melanoma.mp. or exp melanoma/ or exp cutaneous melanoma/

9. 1 or 2 or 3 or 4 or 5 or 6 or 7

10. 8 and 9

Cochrane library, $n=23$ trials

1. melanoma OR cutaneous melanoma

2. Vectra

3. Three-dimensional imaging

4. 3D total Body photography

5. total-Body 3D photography

6. complete Body photography

7. Body photography

8. \#2 OR \#3 OR \#4 OR \#5 OR \#6 OR \#7

9. \#1 AND \#8

1 "mp" refers to an ovid syntax term standing for multi-purpose. In general, an MP search searches the title, original title, abstract, subject heading, name of the substance, and registry word fields. 


\subsection{Selection of Studies}

Three authors (T.S., A.H., M.V.H.) independently screened titles and abstracts for eligibility that were identified in the electronic database searches. For records that were considered relevant according to title and abstract screening, full-text articles were obtained, and inclusion and exclusion criteria were applied by the same three authors. Whenever discrepancies arose, a resolution was achieved by discussion with another independent author (C.B., A.W., T.J.B., T.B., M.E.).

\subsection{Data Extraction and Management}

Information for each included study regarding study design, baseline characteristics of the included population, risk factors for melanoma, imaging technique, and intervals of TBP, follow-up strategy, main outcomes, and study limitations were collected and summarized independently by two authors (A.H., M.V.H.). Data were extracted to an internally piloted data extraction spreadsheet using Microsoft Excel 2010. If multiple reports of a primary study were identified, all available data were extracted. According to the principles of evidence-based medicine, we also decided to contact study authors for clarification in case of inconsistencies in reporting or overlapping study populations were identified. However, this was not the case for any of the identified records. The baseline characteristics and the outcomes of interest of each study were described qualitatively within the text, as a quantitative synthesis was not feasible due to the high heterogeneity of included studies.

\subsection{Assessment of Methodological Quality}

The risks of bias and applicability of the included studies were assessed by two reviewers (A.H., T.S.) independently using a modified version of the QUADAS-2 checklist [22]. QUADAS-2 consists of the four key domains "patient selection", "index test", "reference standard", and "flow and timing". Each domain was assessed by the two raters in terms of risk of bias. The first three domains were additionally rated in terms of concerns regarding applicability. Any disagreement was resolved by consensus with another review author (M.V.H.).

\section{Results}

\subsection{Study Identification}

We identified 1573 references through database searching and cross-referencing in guidelines. After removal of duplicates and title-abstract screening, 48 records underwent full-text review. Thirty records were dismissed as the study design did not meet the predefined eligibility criteria or as the record did not refer to a study. In addition, two further duplicates were identified, and two references did not present any results. Hence, 14 published reports referring to 13 independent studies published between 1997 and 2020 with an overall sample size of $n=12082$ (range 100-4692) were included in qualitative analysis (Figure 1). 


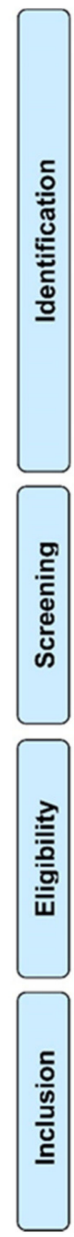

Records identified through

database research $(n=1561)$

- Medline $(n=255)$

- Embase $(n=1283)$

- Central $(n=23)$

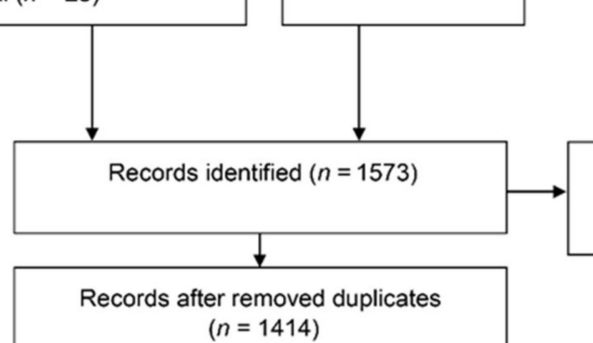

Duplicates removed

$(n=159)$

$(n=1414)$

Additionally

identified records

$(n=12)$

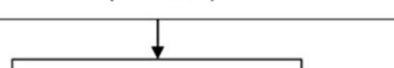

Records screened

Records excluded

$(n=1366)$

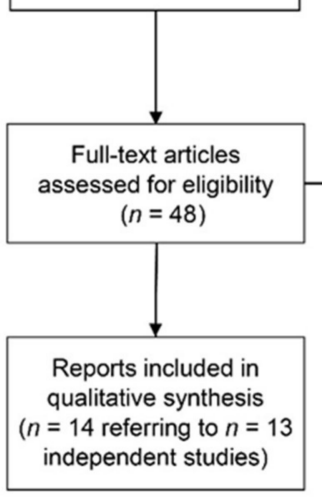

Full-text articles excluded $(n=34)$

- Duplicate $(n=2)$

- Inappropriate design $(n=30)$

No results $(n=2)$

Figure 1. Flow chart of the literature identification process according to the PRISMA guidelines.

\subsection{Study Characteristics}

Seven studies were conducted in the USA [23-29], and three in Australia [30-32]. One study was performed in Europe [33,34], one in New Zealand [35], and one in Israel [36] (Table 2). All included studies investigated 2-D TBP while none investigated 3-D TBP. However, four studies did not describe the methods of imaging in detail [24,25,27,29], while in eight studies TBP was performed by using standardized poses or views with a systematic series of photos [26,28,30-36]. In the study performed by Drugge et al., a semi-automated TBP system was deployed which captured images simultaneously using 25 cameras [23,29]. While in six studies TBP was performed with serial imaging [23,29,31,33-36], in four studies only baseline TBP was performed [26,28,30,32]. In addition, ten studies also implemented dermoscopy [23,26,28-36]. SDDI was only conducted in four studies [31,33-36]. In most studies, 12-27 macroscopic images were acquired with conventional cameras to capture the entire skin surface in 2-D [26,30-32,36]. 
Table 2. Baseline Characteristics of the Included Studies.

\begin{tabular}{|c|c|c|c|c|c|}
\hline Study & Design & Population & Risk Factors for Inclusion & Imaging Technique & Baseline vs. Serial TBP \\
\hline \multicolumn{6}{|c|}{ Prospective Trials } \\
\hline Banky 2005 & $\begin{array}{l}\text { prospective } \\
\text { single cohort }\end{array}$ & $\begin{array}{c}>16 \text { years } \\
\text { median age } 38 \text { years (range } 16-74) \\
n=309(\text { female } n=168, \text { male } n=141) \\
\text { Australia }\end{array}$ & $\begin{array}{l}\qquad 4 \text { dysplastic nevi } \\
\quad>100 \text { nevi } \\
\text { positive family history of melanoma } \\
\text { positive personal history of melanoma }\end{array}$ & $\begin{array}{c}14 \text { baseline photographs } \\
35 \text { mm single-lens reflex } \\
\text { camera } \\
\text { dermoscopy allowed, no SDDI }\end{array}$ & baseline TBP \\
\hline Goodson 2010 & $\begin{array}{l}\text { prospective } \\
\text { single cohort }\end{array}$ & $\begin{array}{c}n=1076 \\
\text { USA }\end{array}$ & $\begin{array}{l}\geq 3 \text { atypical nevi } \\
>50 \text { nevi } \\
\text { personal history of melanoma } \\
\text { positive family history of melanoma } \\
\text { extensive lentiginosis }\end{array}$ & $\begin{array}{l}\text { approx. } 27 \text { regional } \\
\text { photographs on standard poses; additional } \\
\text { photographs were taken to monitor } \\
\text { atypical lesions in other regions } \\
\text { FinePix S2 Pro digital camera } \\
\text { dermoscopy allowed, no SDDI }\end{array}$ & baseline TBP \\
\hline Kelly 1997 & $\begin{array}{l}\text { prospective } \\
\text { single cohort }\end{array}$ & $\begin{array}{c}>18 \text { years } \\
\text { mean age } 37 \text { years (range 18-67) } \\
n=278(\text { female } n=162, \text { male } n=116) \\
\text { Australia }\end{array}$ & dysplastic melanocytic nevi & $\begin{array}{l}\text { systematic set of } 14 \text { baseline photographs } \\
\text { with definition of standard views } \\
\text { epiluminescence microscopy }\end{array}$ & baseline TBP \\
\hline Moloney 2014 & $\begin{array}{l}\text { prospective } \\
\text { single cohort }\end{array}$ & $\begin{array}{c}>18 \text { years } \\
\text { median age } 53 \text { years (range 21-85) } \\
n=311 \\
\text { Australia }\end{array}$ & $\begin{array}{l}\text { 4 groups: } \\
\text { (i) personal history of at least one invasive } \\
\text { melanoma and dysplastic nevus syndrome } \\
\text { (ii) personal history of at least one invasive } \\
\text { melanoma and a family history of at least } \\
\text { three first-degree or second-degree relatives } \\
\text { with a confirmed history of } \\
\text { malignant melanoma } \\
\text { (iii) personal history of at least two primary } \\
\text { invasive melanomas with at least one } \\
\text { occurring in the 10 years prior to recruitment } \\
\text { for patients with only two melanomas } \\
\text { (iv) confirmed CDKN2A (OMIM 600160) or } \\
\text { CDK4 (OMIM123829) gene mutation }\end{array}$ & $\begin{array}{c}\text { 12-24 digital high-resolution photographs } \\
\text { according to a standardized protocol } \\
\text { SDDI allowed }\end{array}$ & serial TBP \\
\hline Nathansohn 2007 & $\begin{array}{l}\text { prospective } \\
\text { single cohort }\end{array}$ & $\begin{array}{c}0-82 \text { years } \\
\text { median age } 34 \text { years } \\
n=895(\text { female } n=401, \text { male } n=494) \\
\text { Israel }\end{array}$ & $\begin{array}{l}>20 \text { nevi or multiple freckles } \\
\text { multiple dysplastic nevi } \\
\text { positive family history of melanoma } \\
\text { children with congenital nevi }\end{array}$ & $\begin{array}{c}12 \text { MP digital single-lens reflex camera and } \\
7 \text { MP digital camera with polarized light } \\
\text { dermoscope } \\
\text { standard set of } 20 \text { photos and photos of } \\
\text { marked lesions }\end{array}$ & serial TBP \\
\hline Salerni 2012 & $\begin{array}{l}\text { prospective } \\
\text { single cohort }\end{array}$ & $\begin{array}{c}\text { mean age } 37 \text { years } \\
n=618(\text { female } n=337, \text { male } n=281) \\
\text { Europe }\end{array}$ & $\begin{array}{c}\text { moderate to severe atypical mole } \\
\text { syndrome }(>100 \text { nevi and/or }>10 \text { atypical } \\
\text { and/or dysplastic nevi) } \\
\text { personal and/or family history of melanoma } \\
\text { carriers of melanoma gene mutations } \\
\text { other cancer risk conditions (congenital } \\
\text { nevus, immunosuppression, } \\
\text { genodermatosis) }\end{array}$ & $\begin{array}{c}\text { standardized digital system for images } \\
\text { (standardized method for total } \\
\text { body mapping) } \\
\text { total-body mapping with } \\
\text { digital images } \\
\text { SDDI allowed }\end{array}$ & serial TBP \\
\hline
\end{tabular}


Table 2. Cont

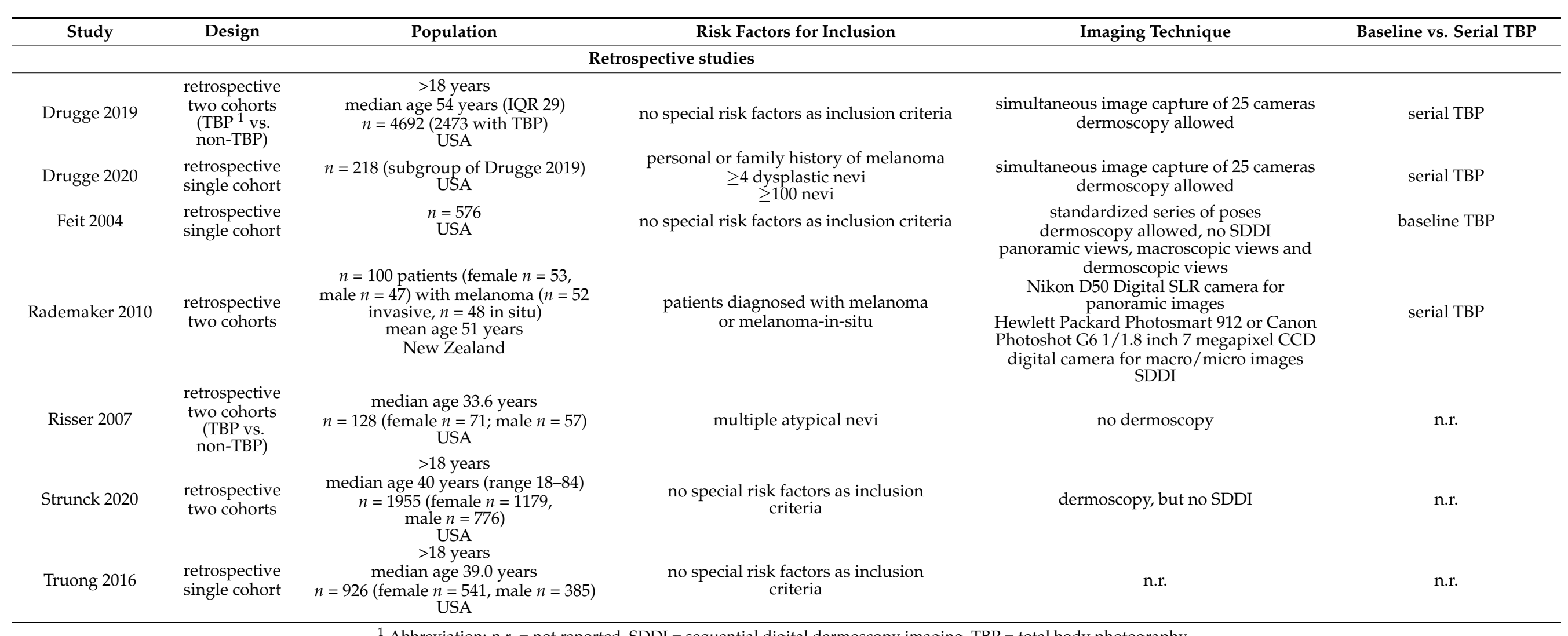

${ }^{1}$ Abbreviation: n.r. $=$ not reported, $\mathrm{SDDI}=$ sequential digital dermoscopy imaging, $\mathrm{TBP}=$ total body photography. 
The selection and inclusion criteria of the screened populations were highly heterogeneous. Risk factors for inclusion differed considerably between the studies. In four publications, no further risk factors were specified for study participation $[23,25,27,28]$ (Table 2).

\subsection{Outcomes}

\subsubsection{Prospective Studies}

Banky et al. performed a cohort study of 309 patients at high risk for melanoma who underwent baseline TBP and were followed up at three-, six-, or twelve-month intervals [32]. Eighteen melanomas were detected. The overall incidence of melanoma was 19 per 1000 person-years. The benign-to-malignant ratio of lesion biopsies was almost 3:1.

In the prospective cohort study reported by Goodson et al., TBP was performed at baseline and patients were clinically followed-up at six- and twelve-month intervals (Figure 2). Outcomes of interest were the biopsy rate, the efficiency of melanoma detection, and melanoma origin (de novo or nevus-derived). In total, 548 biopsies were performed in 1076 patients (273 during the initial visit and 275 on follow-up) [26]; 61\% of the 275 biopsies at follow-up were performed due to photographic evaluation. At follow-up, 12 melanomas were detected, 5 were invasive. Five of them presented as changing and two as new lesions.

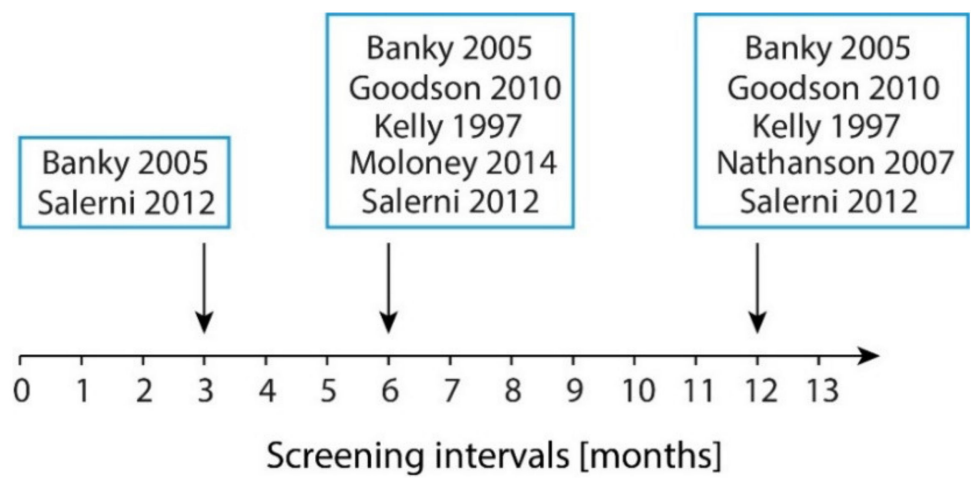

Figure 2. Imaging intervals of the prospective trials. Screening intervals according to intervals in months.

Kelly et al. assessed 278 patients with dysplastic melanocytic nevi in a prospective cohort study [30]. Patients were followed up for a mean of 42 months, 210 biopsies were obtained. Overall, 20 new melanomas ( $n=12$ invasive, $n=8$ in situ) were detected in 16 patients. The age-adjusted incidence was calculated to $1835 / 100,000$ person-years. Notably, 11 melanomas were detected due to comparison with baseline photographs.

Moloney et al. performed a prospective observational study in Australia to examine the effect of regular full body examination in combination with dermoscopy and TBP [31]. SDDI was performed for ambiguous lesions. In 311 patients, 75 primary melanomas were detected, 14 of them at baseline visit; 38\% were detected using TBP, and 39\% with SDDI. Of the 770 excised lesions, 441 were melanocytic, including 82 melanomas, representing a 4.4:1 benign-to-malignant melanoma ratio. The overall rate of melanomas identified during follow-up per study year was 0.08 .

Nathansohn et al. established a pigmented lesions clinic based on a digital photography studio with TBP and dermoscopy. In the first 20 months of the prospective study, 895 patients were examined, 206 of them had follow-up visits [36]; 236 suspicious lesions were excised with 7 emerging as melanomas.

Taken together in all six prospective studies 7 to 98 melanomas were detected. Two of these studies indicated that up to 11 out of 20 melanomas were detected due to TBP. Three studies specified the number needed to excise, ranging from 3:1 to 11.9:1. Altogether the number of biopsies ranged from 210 to 1152 biopsies (Tables 3 and 4). 
Table 3. Summary of the Outcomes of Interest of the Included Studies without a Relevant Comparison of TBP vs. Non-TBP.

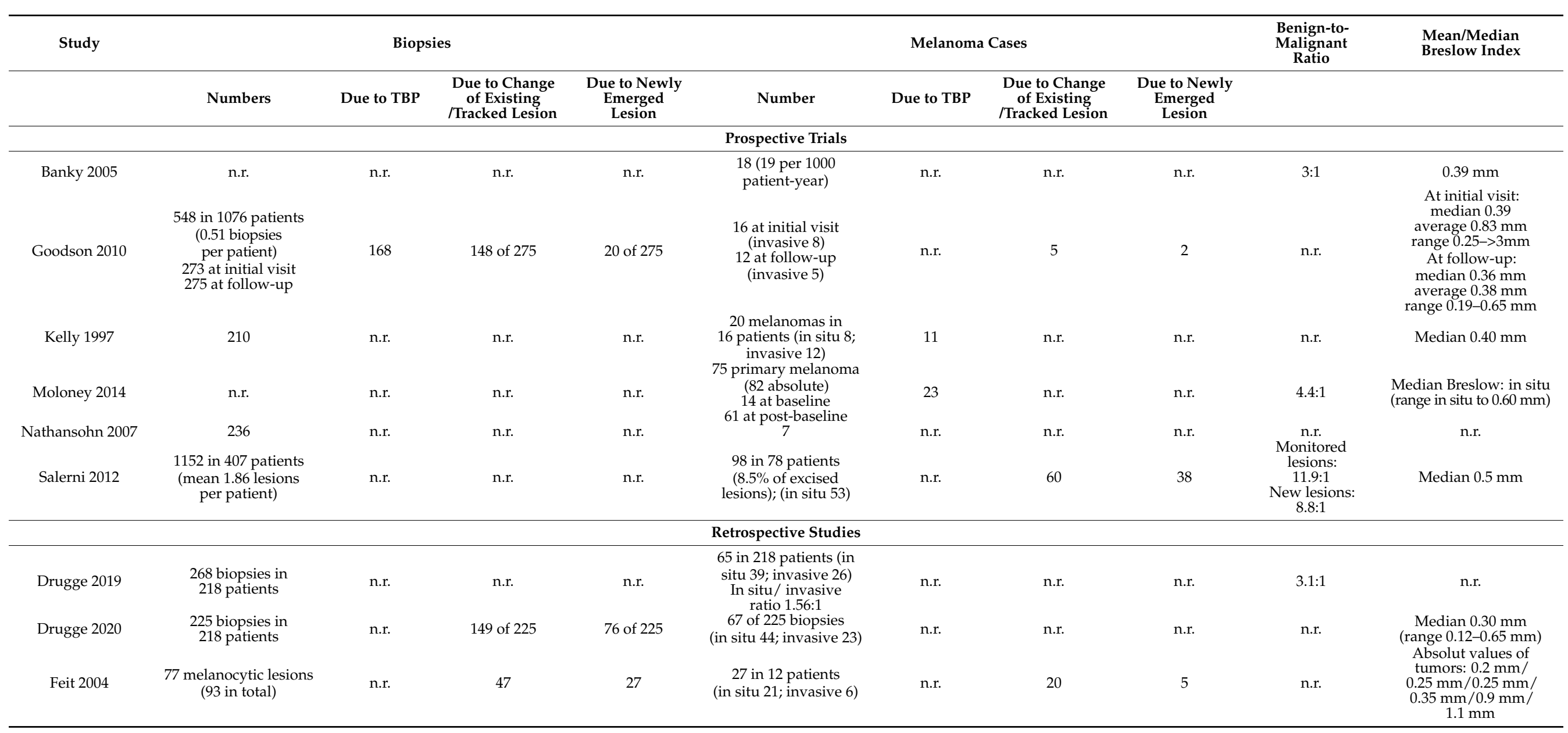


Table 4. Summary of the Outcomes of Interest of the Included Studies with a Comparison of TBP vs. Non-TBP.

\begin{tabular}{|c|c|c|c|c|c|c|c|c|c|c|}
\hline \multirow[t]{2}{*}{ Study } & \multicolumn{4}{|c|}{ Biopsies } & \multicolumn{4}{|c|}{ Melanoma Cases } & \multirow{2}{*}{$\begin{array}{c}\text { Benign-to- } \\
\text { Malignant } \\
\text { Ratio }\end{array}$} & \multirow[t]{2}{*}{ Mean/Median Breslow Index } \\
\hline & Numbers & Due to TBP & $\begin{array}{l}\text { Due to Change } \\
\text { of Existing } \\
\text { /Tracked Lesion }\end{array}$ & $\begin{array}{l}\text { Due to Newly } \\
\text { Emerged } \\
\text { Lesion }\end{array}$ & Number & Due to TBP & $\begin{array}{l}\text { Due to Change } \\
\text { of Existing } \\
\text { /Tracked Lesion }\end{array}$ & $\begin{array}{l}\text { Due to Newly } \\
\text { Emerged } \\
\text { Lesion }\end{array}$ & & \\
\hline \multicolumn{11}{|c|}{ Retrospective Studies } \\
\hline Rademaker 2010 & n.r. & n.r. & n.r. & n.r. & n.r. & n.r. & n.r. & n.r. & n.r. & $\begin{array}{c}\text { Breslow index with TBP } \\
\text { (vs. register data): } \\
<0.75 \mathrm{~mm}: 69 \% \text { (vs. } 52 \% \text { ) } \\
0.76-1.49: 21 \% \text { (vs. 22\%) } \\
1.5-3.0: 8 \% \text { (vs. } 15 \% \text { ) } \\
>3.0 \mathrm{~mm}: 2 \% \text { (vs. } 11 \% \text { ) } \\
\text { First visit average } 0.87 \mathrm{~mm} \\
\text { (range } 0.3-3.35 \text { ) } \\
\text { Follow-up average } 0.67 \\
\text { (range } 0.22-1.60 \mathrm{~mm}\end{array}$ \\
\hline Risser 2007 & $\begin{array}{l}\text { Mean: } 0.81 \\
\text { TBSE: } 0.82(51 \text { in } \\
29 \text { patients) } \\
\text { TBP: } 0.8 \text { (53 in } \\
28 \text { patients) }\end{array}$ & n.r. & n.r. & n.r. & $\begin{array}{c}\text { TBSE: } 3 \text { in } \\
19 \text { patients } \\
\text { TBP: } 0 \text { in } 16 \text { patients }\end{array}$ & n.r. & n.r. & n.r. & n.r. & Absolute: $0.3,0.44$ and $1.1 \mathrm{~mm}$ \\
\hline Strunck 2020 & n.r. & n.r. & n.r. & n.r. & $\begin{array}{c}121 \text { (in situ 51, } \\
\text { invasive 70) }\end{array}$ & $\begin{array}{l}54 \text { changing; } \\
11 \text { new }\end{array}$ & 65 & 12 & & $\begin{array}{c}\text { Median depth } \\
\text { - } 0.33 \text { mm in follow-up group } \\
\text { (range 0.11-1.5) } \\
\text { - } \quad 0.83 \text { mm in control group } \\
\text { without follow-up } \\
\text { (range 0.11-3.3) } \\
\text { Median depth, if TBP was used: } \\
-\quad 0.31 \mathrm{~mm} \text { (range } 0.11-1.5 \text { ) } \\
\text { Median depth without use } \\
\text { of TBP: } \\
\text { - } \quad 0.48 \mathrm{~mm}(0.10-3.3)\end{array}$ \\
\hline Truong 2016 & $\begin{array}{l}\text { Pre-TBP } 3489 \\
\text { biopsies in } \\
589 \text { patients } \\
\text { (mean 5.92) } \\
\text { Post-TBP 921 } \\
\text { biopsies in } \\
589 \text { patients } \\
\text { (mean 1.56) }\end{array}$ & n.r. & n.r. & n.r. & $\begin{array}{c}\text { Pre-TBP: } \\
278 \text { biopsies with } \\
32 \text { melanomas } \\
\text { (in situ 14; invasive 18) } \\
\text { Post-TBP: } \\
1419 \text { biopsies with } \\
93 \text { melanomas } \\
\text { (in situ 46; invasive 47) }\end{array}$ & n.r. & n.r. & n.r. & $\begin{array}{l}\text { Pre-TBP } 7.7 \\
\text { Post-TBP } 14.3\end{array}$ & $\begin{array}{c}\text { Range: } \\
\text { - Pre-TBP: 0.2-3.0 mm } \\
\text { - Post-TBP: } 0.11-2.1 \mathrm{~mm}\end{array}$ \\
\hline
\end{tabular}




\subsubsection{Retrospective Studies and Chart Reviews}

In the retrospective study by Drugge et al., 4692 patients were analyzed regarding patient characteristics, self-reported melanoma risk factors, and the usage of TBP [23]; 2473 of the patients were scanned at least once with TBP, 268 biopsies were obtained in 218 patients. At least one malignant lesion was identified in 65 of the 218 patients (30\%). The number needed to excise one melanoma for all 268 lesions was 3:1. The ratio of melanoma in situ to invasive melanoma was 1.56:1. Using data from the same cohort, the frequency of TBP and the invasion depth of identified melanoma were correlated in 218 patients. In total, 225 lesions were biopsied, 67 (29.8\%) of which were malignant, including 44 in situ and 23 invasive melanomas [29]. The minimum interval between baseline and a follow-up TBP session to identify a new invasive melanoma was 1.29 years.

Feit et al. reported the results of a retrospective study including 576 patients [28]; 93 suspicious lesions were excised of which 77 were melanocytic. Photographic assistance identified 12 patients with 27 histologically confirmed melanomas $(n=21$ in situ; $n=6$ invasive); $74 \%$ of the melanomas ( $n=27$ ) were biopsied due to changes from baseline while $19 \%$ were biopsied because they newly emerged.

The retrospective registry review of two cohorts by Rademaker et al. investigated demographic and histological data from 100 melanomas diagnosed through self-referred TBP and SDDI service compared to those diagnosed through traditional methods [35]. Fifty-two invasive and 48 in situ melanomas were identified; 48 were diagnosed at the first visit and the remaining by serial digital imaging.

Risser et al. compared biopsy numbers in 946 patients with multiple atypical nevi in their first year of care who received either total body skin examination alone or in combination with TBP [24]. The mean number of performed biopsies was similar in both groups (skin examination only vs. skin examination plus TBP: 0.82 vs. 0.8 ). Three melanomas were diagnosed in 19 patients who did not receive TBP, whereas no melanoma was diagnosed in 16 patients receiving TBP.

Salerni et al. analyzed the use of TBP and dermoscopy in 618 high-risk melanoma patients. A total of 1152 lesions in 407 patients were excised during the surveillance period, corresponding to a mean of 2.83 lesions per patient during a 10-year follow-up period (global excision rate 1.86 per patient in 618 patients) [33,34]; 98 melanomas were detected in 78 patients $(n=53$ in situ), comprising $8.5 \%$ of excised lesions. Sixty melanomas were tracked lesions (benign-to-malignant ratio 11.9:1) while 38 melanomas newly emerged (benign-to-malignant ratio 8.8:1).

In the retrospective study performed by Strunck et al., 121 melanomas were diagnosed among 1955 patients receiving TBP (51 melanoma in situ, 70 invasive melanomas) [27]. Of the 121 biopsies, 66 (54.5\%) were performed due to suspicious photographs. Twelve of $121(9.9 \%)$ melanomas newly emerged. TBP identified 11 of them $(91.6 \%)$. In contrast, TBP identified 54 of $65(83 \%)$ melanomas which were tracked as changing lesions.

Truong et al. reviewed the records of 926 patients who received TBP and had two or more follow-up visits over two years or longer [25]. Patients with TBP received 1.56 biopsies on average. In 1419 biopsies 93 primary melanomas were detected (49\% melanoma in situ), corresponding to a combined benign-to-malignant ratio of 14.3:1.

Altogether in seven retrospective studies or chart reviews the number of invasive melanomas were reported in six studies and ranged from 0 to 70 . The number needed to excise was specified in two studies and ranged from 3.1:1 to 14.3:1. The number of biopsies in patients with TBP ranged from 53 to 921 biopsies (Tables 3 and 4).

\subsection{Breslow Index of Invasive Melanoma}

The reported depth of detected melanoma varied across all studies (Tables 3 and 4). However, individuals undergoing TBP showed a trend towards a lower Breslow's thickness. Patients diagnosed by TBP and SDDI screening had thinner melanomas compared to the registry data in the study by Rademaker et al. $(69 \%$ vs. $52 \%<0.75 \mathrm{~mm} ; 1.9 \%$ vs. $10.8 \%$ $>3 \mathrm{~mm}$ ) [35]. Additionally, a lower index was associated with having one or more follow-up 
visits (median 0.83 vs. $0.33 \mathrm{~mm}$ ) and photographic review (median 0.31 vs. $0.48 \mathrm{~mm}$ ) in the study by Strunck et al. [27]. The median depth was $0.31 \mathrm{~mm}$ (range 0.11-1.5) if TBP could be used compared to $0.48 \mathrm{~mm}(0.10-3.3)$ without consulting of TBP. Additionally, depths of tumors detected with TBP ranged from 0.11 to $2.1 \mathrm{~mm}$ vs. 0.2 to $3.0 \mathrm{~mm}$ for those detected without TBP in the study by Truong et al. [25].

\subsection{Methodological Quality of Included Studies}

Overall, the included studies were judged to be of unclear methodological concern (Figure 3). At least half of the studies were at high or unclear risk of bias for "flow and timing" and all studies were at high risk for bias regarding the "reference standard", mostly since it was unclear whether the reference standard results had been interpreted without knowledge of the results of the index test. Approximately one-third of the studies showed an increased risk in the domain "patient selection" due to unclear sampling of participants. An additional third of the studies had an increased risk in the domain "index test" as it remained unclear if the index test results had been interpreted without knowledge of the results of the reference standard. However, the applicability of study findings was of low concern for the majority of studies in the domains "index test" and "patient selection", while the applicability was of unclear or high concern for the domain "reference standard" in less than $20 \%$ of the studies.

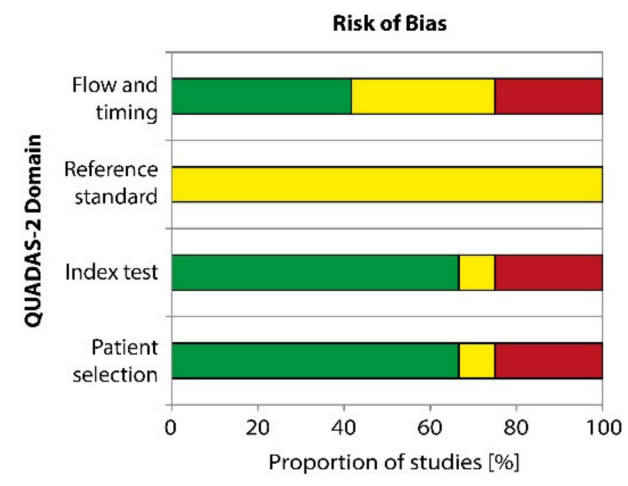

Concerns regarding applicability

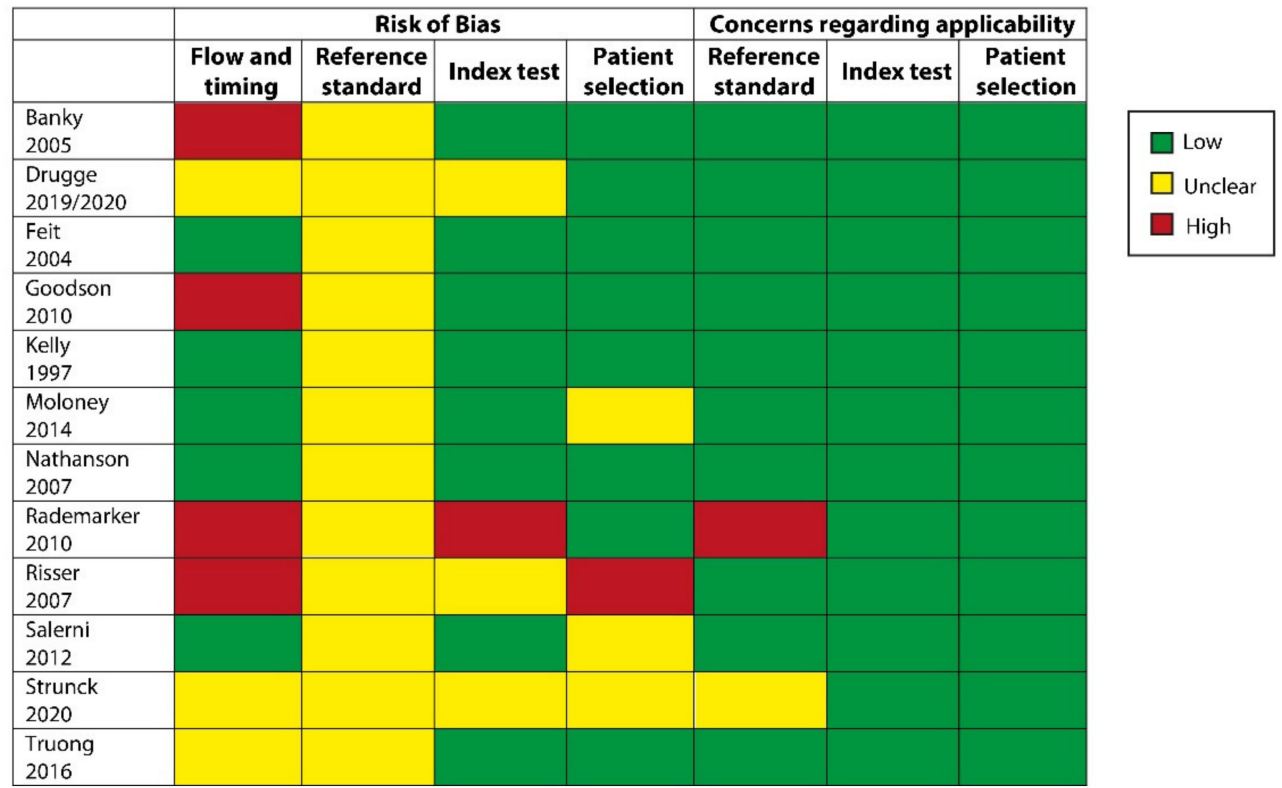

Figure 3. Risk of bias and applicability concerns graph: review authors' judgments about each domain presented as percentages across included studies. Risk of bias and applicability concerns summary: review authors' judgments about each domain for each included study. 


\section{Discussion}

In this study, we aimed to investigate the value of TBP in the early detection of melanoma. Overall, we have identified 14 studies with an overall sample size of $n=12,082$ highlighting that individuals undergoing TBP showed a trend towards a lower Breslow's thickness and a higher proportion of in situ melanomas compared to those without TBP. In addition, our results show that the use of TBP can improve the early detection of melanoma in high-risk populations.

For the early detection and thus secondary prevention of melanoma, there are two distinct strategies to select the target population. Firstly, untargeted mass screening programs can be performed (population-based screening) regardless of individual risk profiles. However, this procedure is only carried out in a few countries such as Germany and is costly due to the high number of screened individuals [37]. In Australia, the number needed to screen to save one life from melanoma was calculated to 25,000 individuals [38]. Hence, the effect in terms of significantly reduced mortality is controversial and considerable resources are needed for a nationwide implementation of such a screening program. Secondly, screening efforts can be restricted to populations at increased risk of developing melanoma. This procedure is more targeted, and the expected effects are larger because the prevalence of the screened population is significantly higher compared with the normal population. The latter procedure was used in the studies reviewed here, yet the definition of risk factors was fairly heterogeneous in keeping with previous reviews on risk prediction models [39]. In most studies, the presence of $>4$ to 5 clinically atypical nevi or a large number $(>100)$ of common nevi was required for investigation by TBP. A positive personal or family history of melanoma was also among the inclusion criteria in some studies while confirmed genetic susceptibility was reported only for two studies. From these data, we conclude that the screened populations had a high to very high risk for melanoma. However, four studies did not specify the risk profiles, underlining that there is currently no consensus on the best risk assessment $[40,41]$. For the conduct of RCTs, risk prediction tools should be harmonized and include a weighting of individual factors to enable cross-population comparisons of distinct regions and ethnicities.

The technical implementation and timing intervals of TBP were similarly heterogeneous as the definition of clinical risk factors. In most studies, 12-30 macroscopic images were acquired with conventional cameras to capture the entire skin surface in two dimensions (2-D TBP). As a limitation, multiple imaging systems were applied with distinct resolutions. Furthermore, the study protocols only referred to standard poses and often did not specify exactly how the images were acquired. Specific anatomic regions such as intertriginous areas, genitals, retroauricular area, or the flexor sides of the extremities may not always be adequately captured with 2-D TBP. Here, the use of 3-D TBP systems in defined postures can help to standardize the image acquisition as they generate a digital 3-D avatar of the imaged person that can be used to analyze and prospectively follow all nevi of interest $[13,37,42]$. Currently, an RCT is ongoing in Australia evaluating the efficacy of 3-D TBP combined with SDDI compared with regular skin examinations which may or may not use 2-D TBP with SDDI. The main outcomes to be prospectively assessed in this study are the number of incisional and excisional biopsies and the Breslow depth of detected melanomas [37]. The number of in situ tumors also represents a valid indicator for the early detection of melanoma.

The results of our study clearly show that 2-D TBP identified a higher proportion of in situ tumors and melanomas with a lower average Breslow thickness compared with the comparison groups without 2-D TBP. The number needed to excise one melanoma varied widely, ranging from 3:1 to 14.3:1. This ratio was better for lesions that arose de novo than for tracked ones. We conclude that the latter need to be assessed with additional methods such as dermoscopy and that the added value of TBP is highest for lesions that arose newly during the surveillance period.

Artificial intelligence (AI) was not used in any of the included studies to evaluate the captured images. The image analysis was performed by the respective physicians 
in all reports. Several landmark studies have recently shown that AI performed on par with dermatologists in the distinction of nevi from melanoma based on dermoscopic images [43-45]. Similarly, future studies are warranted to investigate whether the analysis of 3-D TBP images using AI is also feasible. AI ultimately should be integrated into 3-D TBP systems to support image analysis, pattern recognition, and detect changes of nevi in sequential examinations. Furthermore, the 3-D TBP images should also be equipped with interfaces to SDDI, which in turn could also be analyzed using AI to make screening efforts more accurate while maintaining cost efficiency.

Overall, our study shows that the use of 2-D TBP can improve the early detection of melanoma in high-risk populations. However, the definition of phenotypic risk factors, technical performance of TBP, and design of the included studies were highly heterogeneous. In the future, harmonized risk prediction tools should be developed to compare distinct populations. 3-D TBP with the generation of digital avatars is a game-changing technology and will enable standardized and gapless image acquisition.

Author Contributions: Conceptualization, T.S., M.V.H. and C.B.; methodology, T.S., A.H. and M.V.H.; formal analysis, A.H., T.S. and M.V.H.; investigation, T.S., A.H. and M.V.H.; resources, A.H., T.S.; data curation, T.S., A.H. and M.V.H. writing - original draft preparation, T.S., A.H. and M.V.H.; writing-review and editing, M.E., T.B., T.J.B., A.W. and C.B.; visualization, A.W.; supervision, C.B. and M.V.H.; project administration, C.B. All authors have read and agreed to the published version of the manuscript.

Funding: This research received no external funding.

Institutional Review Board Statement: Not applicable.

Informed Consent Statement: Not applicable.

Data Availability Statement: The data presented in this study are available on request from the corresponding author.

Conflicts of Interest: The authors declare no conflict of interest.

\section{References}

1. Garbe, C.; Keim, U.; Eigentler, T.K.; Amaral, T.; Katalinic, A.; Holleczek, B.; Martus, P.; Leiter, U. Time trends in incidence and mortality of cutaneous melanoma in Germany. J. Eur. Acad. Dermatol. Venereol. 2019, 33, 1272-1280. [CrossRef]

2. Glazer, A.M.; Winkelmann, R.R.; Farberg, A.S.; Rigel, D.S. Analysis of Trends in US Melanoma Incidence and Mortality. JAMA Dermatol. 2017, 153, 225-226. [CrossRef]

3. Miller, K.D.; Nogueira, L.; Mariotto, A.B.; Rowland, J.H.; Yabroff, K.R.; Alfano, C.M.; Jemal, A.; Kramer, J.L.; Siegel, R.L. Cancer treatment and survivorship statistics, 2019. CA Cancer J. Clin. 2019, 69, 363-385. [CrossRef]

4. International Agency for Research on Cancer; World Health Organisation (WHO). GLOBOCAN 2018: Estimated Cancer Incidence, Mortality, and Prevalence Worldwide in 2018. Available online: http:/ / globocan.iarc.fr (accessed on 15 October 2019).

5. Ugurel, S.; Rohmel, J.; Ascierto, P.A.; Flaherty, K.T.; Grob, J.J.; Hauschild, A.; Larkin, J.; Long, G.V.; Lorigan, P.; McArthur, G.A.; et al. Survival of patients with advanced metastatic melanoma: The impact of novel therapies-Update 2017. Eur. J. Cancer 2017, 83, 247-257. [CrossRef] [PubMed]

6. Weiss, S.A.; Wolchok, J.D.; Sznol, M. Immunotherapy of Melanoma: Facts and Hopes. Clin. Cancer Res. 2019, $25,5191-5201$. [CrossRef]

7. Green, A.C.; Baade, P.; Coory, M.; Aitken, J.F.; Smithers, M. Population-based 20-year survival among people diagnosed with thin melanomas in Queensland, Australia. J. Clin. Oncol. 2012, 30, 1462-1467. [CrossRef] [PubMed]

8. Lo, S.N.; Scolyer, R.A.; Thompson, J.F. Long-Term Survival of Patients with Thin (T1) Cutaneous Melanomas: A Breslow Thickness Cut Point of $0.8 \mathrm{~mm}$ Separates Higher-Risk and Lower-Risk Tumors. Ann. Surg. Oncol. 2018, 25, 894-902. [CrossRef]

9. McKinnon, J.G.; Yu, X.Q.; McCarthy, W.H.; Thompson, J.F. Prognosis for patients with thin cutaneous melanoma: Long-term survival data from New South Wales Central Cancer Registry and the Sydney Melanoma Unit. Cancer 2003, 98, $1223-1231$. [CrossRef] [PubMed]

10. Augustin, M.; Stadler, R.; Reusch, M.; Schafer, I.; Kornek, T.; Luger, T. Skin cancer screening in Germany-Perception by the public. J. Dtsch Dermatol. Ges. 2012, 10, 42-49. [CrossRef] [PubMed]

11. Usher-Smith, J.A.; Kassianos, A.P.; Emery, J.D.; Abel, G.A.; Teoh, Z.; Hall, S.; Neal, R.D.; Murchie, P.; Walter, F.M. Identifying people at higher risk of melanoma across the U.K.: A primary-care-based electronic survey. Br. J. Dermatol. 2017, 176, 939-948. [CrossRef] 
12. Williams, L.H.; Shors, A.R.; Barlow, W.E.; Solomon, C.; White, E. Identifying Persons at Highest Risk of Melanoma Using Self-Assessed Risk Factors. J. Clin. Exp. Dermatol. Res. 2011, 2, 1000129. [PubMed]

13. Rayner, J.E.; Laino, A.M.; Nufer, K.L.; Adams, L.; Raphael, A.P.; Menzies, S.W.; Soyer, H.P. Clinical Perspective of 3D Total Body Photography for Early Detection and Screening of Melanoma. Front. Med. (Lausanne) 2018, 5, 152. [CrossRef]

14. Halpern, A.C. Total body skin imaging as an aid to melanoma detection. Semin. Cutan. Med. Surg. 2003, 22, 2-8. [CrossRef] [PubMed]

15. Halpern, A.C. The use of whole body photography in a pigmented lesion clinic. Dermatol. Surg. 2000, 26, 1175-1180.

16. Young, A.T.; Vora, N.B.; Cortez, J.; Tam, A.; Yeniay, Y.; Afifi, L.; Yan, D.; Nosrati, A.; Wong, A.; Johal, A.; et al. The role of technology in melanoma screening and diagnosis. Pigment. Cell Melanoma Res. 2020, 18. [CrossRef] [PubMed]

17. Adler, N.R.; Kelly, J.W.; Guitera, P.; Menzies, S.W.; Chamberlain, A.J.; Fishburn, P.; Button-Sloan, A.E.; Heal, C.; Soyer, H.P.; Thompson, J.F. Methods of melanoma detection and of skin monitoring for individuals at high risk of melanoma: New Australian clinical practice guidelines. Med. J. Aust. 2019, 210, 41-47. [CrossRef] [PubMed]

18. Moher, D.; Liberati, A.; Tetzlaff, J.; Altman, D.G.; Group, P. Preferred reporting items for systematic reviews and meta-analyses: The PRISMA Statement. Open Med. 2009, 3, e123-e130. [PubMed]

19. McInnes, M.D.F.; Moher, D.; Thombs, B.D.; McGrath, T.A.; Bossuyt, P.M.; Clifford, T.; Cohen, J.F.; Deeks, J.J.; Gatsonis, C.; Hooft, L.; et al. Preferred Reporting Items for a Systematic Review and Meta-analysis of Diagnostic Test Accuracy Studies: The PRISMA-DTA Statement. JAMA 2018, 319, 388-396. [CrossRef] [PubMed]

20. Salameh, J.P.; Bossuyt, P.M.; McGrath, T.A.; Thombs, B.D.; Hyde, C.J.; Macaskill, P.; Deeks, J.J.; Leeflang, M.; Korevaar, D.A.; Whiting, P.; et al. Preferred reporting items for systematic review and meta-analysis of diagnostic test accuracy studies (PRISMADTA): Explanation, elaboration, and checklist. BMJ 2020, 370, m2632. [CrossRef] [PubMed]

21. Higgins, J.P.T.; Thomas, J.; Chandler, J.; Cumpston, M.; Li, T.; Page, M.J.; Welch, V.A. (Eds.) Cochrane Handbook for Systematic Reviews of Interventions Version 6.0; (Updated July 2019); Cochrane: London, UK, 2019; Available online: www.training.cochrane. org/handbook (accessed on 11 November 2020).

22. Whiting, P.F.; Rutjes, A.W.; Westwood, M.E.; Mallett, S.; Deeks, J.J.; Reitsma, J.B.; Leeflang, M.M.; Sterne, J.A.; Bossuyt, P.M.; Group, Q. QUADAS-2: A revised tool for the quality assessment of diagnostic accuracy studies. Ann. Intern. Med. 2011, 155, 529-536. [CrossRef]

23. Drugge, E.D.; Okundaye, O.I.; Sarac, R.M.; Drugge, R.J. Melanoma screening using patient self-assessed risk and total body photography. Dermatol. Online J. 2019, 25, 15.

24. Risser, J.; Pressley, Z.; Veledar, E.; Washington, C.; Chen, S.C. The impact of total body photography on biopsy rate in patients from a pigmented lesion clinic. J. Am. Acad. Dermatol. 2007, 57, 428-434. [CrossRef] [PubMed]

25. Truong, A.; Strazzulla, L.; March, J.; Boucher, K.M.; Nelson, K.C.; Kim, C.C.; Grossman, D. Reduction in nevus biopsies in patients monitored by total body photography. J. Am. Acad. Dermatol. 2016, 75, 135-143.e135. [CrossRef] [PubMed]

26. Goodson, A.G.; Florell, S.R.; Hyde, M.; Bowen, G.M.; Grossman, D. Comparative analysis of total body and dermatoscopic photographic monitoring of nevi in similar patient populations at risk for cutaneous melanoma. Dermatol. Surg. 2010, 36, 1087-1098. [CrossRef]

27. Strunck, J.L.; Smart, T.C.; Boucher, K.M.; Secrest, A.M.; Grossman, D. Improved melanoma outcomes and survival in patients monitored by total body photography: A natural experiment. J. Dermatol. 2020, 47, 342-347. [CrossRef]

28. Feit, N.E.; Dusza, S.W.; Marghoob, A.A. Melanomas detected with the aid of total cutaneous photography. Br. J. Dermatol. 2004, 150, 706-714. [CrossRef]

29. Drugge, E.D.; Sarac, R.M.; Elston, D.M.; Drugge, R.J. Correlation of total body photography frequency and invasive melanoma depth. J. Am. Acad. Dermatol. 2020, 82, 768-769. [CrossRef]

30. Kelly, J.W.; Yeatman, J.M.; Regalia, G.; Mason, G.; Henham, A.P. A high incidence of melanoma found in patients with multiple dysplastic naevi by photographic surveillance. Med. J. Aust. 1997, 167, 191-194. [CrossRef] [PubMed]

31. Moloney, F.; Guitera, P.; Coates, E.; Haass, N.; Ho, K.; Khoury, R.; Mann, G.; Menzies, S. Sequential digital dermoscopic imaging and total body photography aid detection of primary melanoma in individuals at high risk: A prospective 5-year follow-up study. Br. J. Dermatol. 2012, 167, 4 .

32. Banky, J.P.; Kelly, J.W.; English, D.R.; Yeatman, J.M.; Dowling, J.P. Incidence of new and changed nevi and melanomas detected using baseline images and dermoscopy in patients at high risk for melanoma. Arch. Dermatol. 2005, 141, 998-1006. [CrossRef]

33. Salerni, G.; Carrera, C.; Lovatto, L.; Marti-Laborda, R.M.; Isern, G.; Palou, J.; Alos, L.; Puig, S.; Malvehy, J. Characterization of 1152 lesions excised over 10 years using total-body photography and digital dermatoscopy in the surveillance of patients at high risk for melanoma. J. Am. Acad. Dermatol. 2012, 67, 836-845. [CrossRef]

34. Salerni, G.; Carrera, C.; Lovatto, L.; Puig-Butille, J.A.; Badenas, C.; Plana, E.; Puig, S.; Malvehy, J. Benefits of total body photography and digital dermatoscopy ("two-step method of digital follow-up") in the early diagnosis of melanoma in patients at high risk for melanoma. J. Am. Acad. Dermatol. 2012, 67, e17-e27. [CrossRef]

35. Rademaker, M.; Oakley, A. Digital monitoring by whole body photography and sequential digital dermoscopy detects thinner melanomas. J. Prim. Health Care 2010, 2, 268-272. [CrossRef] [PubMed]

36. Nathansohn, N.; Orenstein, A.; Trau, H.; Liran, A.; Schachter, J. Pigmented lesions clinic for early detection of melanoma: Preliminary results. Isr. Med. Assoc. J. 2007, 9, 708-712. [PubMed] 
37. Primiero, C.A.; McInerney-Leo, A.M.; Betz-Stablein, B.; Whiteman, D.C.; Gordon, L.; Caffery, L.; Aitken, J.F.; Eakin, E.; Osborne, S.; Gray, L.; et al. Evaluation of the efficacy of 3D total-body photography with sequential digital dermoscopy in a high-risk melanoma cohort: Protocol for a randomised controlled trial. BMJ Open 2019, 9, e032969. [CrossRef] [PubMed]

38. Gilmore, S. Melanoma screening: Informing public health policy with quantitative modelling. PLoS ONE 2017, 12, e0182349. [CrossRef]

39. Kaiser, I.; Pfahlberg, A.B.; Uter, W.; Heppt, M.V.; Veierod, M.B.; Gefeller, O. Risk Prediction Models for Melanoma: A Systematic Review on the Heterogeneity in Model Development and Validation. Int. J. Environ. Res. Public Health 2020, 17, 7919. [CrossRef]

40. Vuong, K.; McGeechan, K.; Armstrong, B.K.; Cust, A.E. Risk prediction models for incident primary cutaneous melanoma: A systematic review. JAMA Dermatol. 2014, 150, 434-444. [CrossRef] [PubMed]

41. Usher-Smith, J.A.; Emery, J.; Kassianos, A.P.; Walter, F.M. Risk prediction models for melanoma: A systematic review. Cancer Epidemiol. Biomarkers Prev. 2014, 23, 1450-1463. [CrossRef] [PubMed]

42. Janda, M.; Soyer, H.P. Using Advances in Skin Imaging Technology and Genomics for the Early Detection and Prevention of Melanoma. Dermatology 2019, 235, 1-3. [CrossRef]

43. Brinker, T.J.; Hekler, A.; Enk, A.H.; Klode, J.; Hauschild, A.; Berking, C.; Schilling, B.; Haferkamp, S.; Schadendorf, D.; Frohling, S.; et al. A convolutional neural network trained with dermoscopic images performed on par with 145 dermatologists in a clinical melanoma image classification task. Eur. J. Cancer 2019, 111, 148-154. [CrossRef] [PubMed]

44. Tschandl, P.; Rinner, C.; Apalla, Z.; Argenziano, G.; Codella, N.; Halpern, A.; Janda, M.; Lallas, A.; Longo, C.; Malvehy, J.; et al. Human-computer collaboration for skin cancer recognition. Nat. Med. 2020, 26, 1229-1234. [CrossRef] [PubMed]

45. Hekler, A.; Kather, J.N.; Krieghoff-Henning, E.; Utikal, J.S.; Meier, F.; Gellrich, F.F.; Upmeier Zu Belzen, J.; French, L.; Schlager, J.G.; Ghoreschi, K.; et al. Effects of Label Noise on Deep Learning-Based Skin Cancer Classification. Front. Med. 2020, 7, 177. [CrossRef] [PubMed] 